\title{
Information Technology Effects on Accident Decreasing with Critical Management of Gas Life Line in Electronic City
}

\author{
Mohammadreza Sadeghi Moghaddam ${ }^{1, *}$, Salameh Azimi ${ }^{2}$, Maryam Nakhostin Ahmadi ${ }^{3}$ \\ ${ }^{1}$ Department of Urban Planning, Qazvin Branch, Islamic Azad University, Qazvin, Iran \\ ${ }^{2}$ Department of Industrial Engineering, Qazvin Branch, Islamic Azad University, Qazvin, Iran \\ ${ }^{3}$ Department of Territorial Design, International University of Chabahar, Chabahar, Iran \\ *Corresponding Author: m.sadeghi62@gmail.com
}

Copyright (C) 2013 Horizon Research Publishing All rights reserved.

\begin{abstract}
Computer communications were developed by industrial revolution and then by improving the network communication as an internet, a new space was made for city that it's called virtual city or electronic city. Accidental events are a kind of critical and managing them as soon as possible is so necessary. Since electronic cities help the manager to have necessary information at critical periods, it plays a significant role for crisis management. This study aimed at developing the electronic city and gas lifelines and managing them by electronic technology. Since, lifelines are fundamental construction and commonly are linear circuit network, which can produce the people lives' necessities. If they're damaged several different accidents and critical will be happened. So in this article gas lifelines were examined practically with Iran conditions and several different designs against critical was presented by using information technology.
\end{abstract}

Keywords Electronic City, Critical Management, Lifeline, Information Technology

\section{Introduction}

Modern society relies entirely on an articulated network of infrastructures, which has assumed a vital role for the system in its whole. Lifelines are, therefore, the networks which are developed on the entire territory to relate and connect the various settlements and points of interest of the different subsystems [1].

Recent experiences have highlighted the extreme importance of the lifelines functioning in the conditions of emergency which follow catastrophic events [2, 3]

With the emergence of various industries, computer and with the advent of subsequent communication network on Internet, the rapid progress of ICT (Information and Communication Technology) emerged the new space and face for the city. It's interpreted to virtual city or electronic city [4]. Information technology is the main origin of the information society that due to the advent of computers, development of telecommunications networks and the increasing necessity to use information. Studies in relation to developing the programs in most countries indicate the central role of ICT in such programs [5]. With the expansion of cities and urbanization and the gradual increase in the number of large cities, especially in developing countries, such as Iran, on the one hand, urban development, increased focusing and accumulation of population and economics and environmental loads on their bed, on the other hand, the more attention to cities, has led to the adoption of multiple roles and functions. Natural and artificial events are the topics that most major cities are faced to. According to unexpected nature of most accident and the need to make quick and correct decisions and operations, basic theoretical knowledge has created a crisis management [6].

Crisis management is said to planning process, public official actions and administration agency which attempt to prevent the crisis by various observations, analysis of the crisis as an integrated, comprehensive and coordinated and by using existing tools or if it occurs they're working to decrease, creating a ready, rapid relief and improvement to achieve normalcy and recon structure work. In other words crisis management is an applied science for looking for various tools by systematic observations, examining and analyzing the crisis for preventing the crisis or if it occurs they help us to reduce it [7]. Lifeline importance role in urban crisis management and interconnected network with one hand and the causes of their economics value make us to have a special attention to them so it's considered to have a joint compiled program for examining the lifeline during event of crisis caused by natural and artificial disasters [8].

Undoubtedly information technology will be affected on reducing accident and crisis management of large cities.

Therefore in this article gas lifeline which is one of the most important and risky lifeline, was examined and crisis 
management by applying several kinds of gas life lines in electronic city were analyzed.

\section{Methodology}

In this project, first the importance of lifelines in city and then gas lifelines, as one of the most important urban infrastructures were examined. Next, Vulnerability of Gas Installations was studied. At the end several different suggestions for gas lifeline controlling and managing were recommended. Finally, some plans for Crisis management were presented.

\section{Life Lines}

Life lines are fundamental structures and generally linear networks which are producing the necessities of citizens. In comparison of buildings, life lines are more important which destructing some parts of the network cause widespread damage of network service to the downstream area.

From the view point of crisis management lifeline damage are affected in two ways. First damaging to components or parts of the networks, causing service discounting to downstream recipients. If the discontinuing service for consumers with high importance or ordinary consumers with mass number and wide range occur can cause the formation of another crisis. The Lifeline damage incidents and crises together can cause major damage such as fire and explosion and the next.

\section{Gas Life Line}

\subsection{Gas installation}

Natural gas provides the needed fuel for domestic consumer, commercial, industrial and bulk fuel power plants and electricity industries. To accomplish such a mission critical facilities, have enough equipment and widespread networks are needed. In our country gas sources can be obtained about 4000 meters deep underground. Gas in underground storage tanks are transferred to centers of consumption with 4000 pounds pressure after purification by high voltage transmission lines and are transferred to the consumption resources and the urban fringe by strong pressure pipeline with about 1000 pounds of pressure. First some branch of the high voltage lines are entered in to the gateway station or city gate station (CGS) for exploitation of natural gas. Gas output from the gate station is entered in to the city lines feeding with 250 pounds of pressure. In the next step the gas station within the city is about 60 pounds and the main subscriber station and the industry will be reduced. Alamaks or branches are the last parts of the gas facilities that are supplying the necessity gas for residential and commercial consumers. Alamaks are entering gas with pounds of pressure in to the gas meters and subscribed installation by the regulator that is installed at the end of the alamaks.

\subsection{Vulnerability of Gas Installation}

We limit our scope study to the urban area where is more effective on health and human lives, then vulnerability of urban gas facility in the country will be examined.

\subsubsection{City Gate Station}

A city gate stations, pressure reduction (CGS) often have high seismic resistance Also, since these stations are located in low populated areas hazardous effects of damage and gas leaks in their lives is less important these stations are more important because they're the heart of the city gas distribution.

\subsubsection{Belt Lines and Feeding Networks}

In the case of 250 pounds pipelines, these lines have high resistance by assuming that all network connections are welded. But due to the high pressure and distribution lines if an event occurs many people will be killed and cutting off the flow has a great effect on people's daily lives.

\subsubsection{Stations within the City}

Usually, pressure reduction stations within the city (TBS \& DRS), consists of two mechanical parts and the brick building station. Since brick wall pieces and the station roof are not usually well controlled, are Likely to be damaged during an earthquake, so retrofitting buildings for these stations is very important.

\subsubsection{Urban Gas Networks}

60 pounds pipes have been implemented from steel and polyethylene which have adequate resistance against earthquake. In some limited instances that the pipe connections are flange kind should be renovated. Gas pressure within the pipe is relatively high. The distribution of these lines, take a lot of risks for human health.

\subsubsection{Branches}

The experimental results shows that gas Alamak have serious vulnerabilities as follows:

1. In the past, side walk valves were installed on the steel Alamak in floor sleeping, since these valves have non-welded joint, so in the case of sever shock and separating some of the connection, gas will be leaking with high pressure and some explosion and fires will be occurred. 2. Alamak upper screw connections are vulnerable areas. If you destroyed the houses walls, there will be a possibility leaking through the screws.

\subsection{Plans for dealing with the crisis}

Plans for crisis management has three important activities:

1. Improvement of seismic installations

2. Immunization with the information technology

3. Crisis management 


\subsubsection{Improvement of Seismic Installations}

In these activities according to follow priorities, some existing facilities should be more resisted and improved in term of seismic.

\section{Side walk valves}

Due to the weakness and multiplicity of valves connection in the city, it's so necessary to collect and improve them.

2. Buildings retrofitting in urban stations (TBS).

3. Necessary measures for flange connections

4. Screw connections

5. Counter and gas regulators

In addition to the improvement of seismic installations and building retrofitting of staff site particularly key personnel and those who have a key role in crisis management, is very important.

\subsubsection{Immunization}

Required measure by using information technology to secure the network against the crisis would follow:

\subsubsection{Block Classification and Stopped Current System}

In the case of damaging to facilities and gas network equipment gas flow in the damaged area should be discontinued, at least we're trying to avoid the gas cutting off in the city.

1. Cutting off systems in city gate stations

2. Net work block classification 250psi and cutting off systems

3. Net work block classification 60psi and cutting off systems

4. Cutting off systems in city stations (TBS \& DRS)

5. Discharging system and gas pressure reduction

It's so clear; for controlling and monitoring system and gas current stopped we have to use information technology and radio communication system for making correct decisions at the shortest possible time.

\subsubsection{Radio Communication Systems and a Central Control Center (CCC)}

Creating the radio communication system that's the base of monitoring and controlling the gas installations and equipments with a central control center building can be used as one of the most detailed information in gas network management. In this system data are sent to central control center from gas equipment and installations by using electronic equipment and data radio communication. Data are being processed and examined by experts and then the best and most efficient method is selected and will be carried out. It's so clear information technology causes monitoring at least time and making correct decision will be based on actual data.

\subsubsection{Seismic Information Systems}

a. Installation of seismograph: when the radio communication systems were set up, the seismograph data were examined and analyzed in central control center. b. Telemetry Pressure and gas flow: Remote monitoring of pressure and flow is possible by installing equipment to cut off gas system in CGS ‘DRS ،TBS stations.

\subsubsection{Crisis Management of Gas Life Line}

A- Prepare an emergency action plan the important issues that must be prepared in the above scheme are as follow:

-Formation of crisis staff and preparing necessary instructions for the movement of personnel

-Organizational plans for dealing with the crisis and preparing and maintaining the workforce and necessary spaces with the needed equipments and facilities.

-Improving the cooperation and interactions with other relevant organizations.

-Purchasing and supplying the needed materials and equipments.

-Electronic equipments installation in gas facilities and radio communication with a central control center.

B- Earthquake drill

The purpose of conducting earthquake drills is understanding the important and necessary points and creating a real sense of crisis at the time of earthquake and related centered defense measures and training the basis to the personnel for being familiar with the company current plans to tackle crisis.

\section{Discussion and Conclusion}

Disasters are one of the most important issues that people and government are facing them each year. They are imposed on a lot of casualties and large financial loses and our country hasn't been excluded from this provision, it's clear the necessary and important issues are applying some measures and strategies for decreasing the resulted possible losses. In this article the role of information technology in crisis management of the gas lifeline were studied and examined, in this article regarding the situation of cities, following suggestions were presented for decreasing the casualties and financial loses.

1-Crisis management plan to protect more cities for reducing vulnerability and human and financial losses due to crisis were prepared in different time periods.

2- Information dissemination and education programs have an effective role in reducing disaster damages and losses. Educational programs through mass media such as television, radio and producing newsletters and brochures, installation of banner advertising for crisis management training of natural and abnormal disasters before occurring. It has a significant role in promoting public awareness and finally it can be more useful in Harm reduction and human and financial losses.

3- Without doubt, using an information technology has an important role in reducing events in the city and establishing a radio communication system that the baseline of monitoring and gas equipments and installations controls with the building of a central control center (CCC) can be 
useful in the design and implementation.

\section{REFERENCES}

[1] F.Ciriannia, F.Fontea, G.Leonardia, F.Scopellitia, SIIV - 5th International Congress - Sustainability of Road Infrastructures Analysis of Lifelines Transportation Vulnerability, Procedia - Social and Behavioral Sciences 53, 29-38, ( 2012 ).

[2] M.Casari, S.J.Wilkie. Sequencing Lifeline Repairs After an Earthquake: An Economic Approach, Journal of Regulatory Economics, 27 (1) 47-65, (2005).

[3] S.E.Chang, N.Nojima. Measuring post-disaster transportation system performance: the 1995 Kobe earthquake in comparative, perspective, Transportation Research Part A: Policy and Practice, 35 (6) 475-494, (2001).
[4] E.Rasulinezhad: Electronic city and mobile commerce, electronic commerce and computer Journal, Vol 36, (2007).

[5] M.Fathian: Characteristics of electronic commerce in the cities, The First International Conference on Electronic Municipality, Tehran,Iran (2007).

[6] M. Abdollahi: Crisis Management In Urban Areas, 3rd edition, Organization of Municipalities Publishing,Iran (2004).

[7] F.NateghAllahi: Crisis management of earthquakes in Iran, 1 st edition, Publication of the Ministry of Foreign Affairs, Iran (1999).

[8] S. AlRasul, Sh. Shariat: Evaluation of methods to reduce impacts on Lifeline Earthquake in Tehran, Second International Conference on Management of Comprehensive Disaster, Tehran,Iran(2006). 